\title{
AKTIVITAS PEMBERIAN KREDIT USAHA PADA PT. BANK PERKREDITAN RAKYAT BATANG KAPAS
}

\author{
Meliza Efriani, Ratna Widayati \\ Akademi Keuangan dan Perbankan Padang \\ ratnawidayati@akbpstie.ac.id
}

\begin{abstract}
The development in the banking industry as well as opening the era of free information has contributed to greater competition between banks. Competition led to similar companies competing to provide the Bank's products and services to increase the Bank's income. With the PT. RB Rod Cotton gave credit to the people around Rod Cotton, one of which is Our Business Credit (KUMI). PT. RB Rod Cotton conduct its lending activities starting from receipt of application Loans, Credit, Credit Agreement, Realization of Credit and Credit Monitoring conducted by the Bank RB Rod Cotton. The purpose of this study was conducted to determine how the credit management at PT. Cotton Trunk Rural Bank in the period 20132015. The method used is a qualitative method. Data collection is done with the data mengumpulkam Development of Credit and Credit Kolektibiltas at. Cotton Trunk Rural Bank. The results could be seen in 2013 and 2015 with loan growth in $201361 \% 201471 \%$ and in $201584 \%$, and the collectibility of the loans in 2013 types of performing loans $89.55 \%$, substandard 3.68, doubt jammed $4.49 \%$ and $2.76 \%$, in 2014 performing loans $89.70 \%$, 4.49\% substandard, doubtful and loss $4.36 \%$ to $1.42 \%$, in 2015 performing loans $89.03 \%$, substandard $4.73 \%$, $4.90 \%$ doubtful, and loss of $1.31 \%$. Thus it can be concluded that the development of credit and credit kolektibiltas at PT. Rural Bank Cotton Trunk good, because $R B$ Rod Cotton was able to reduce the loan from the years 2013-2015.
\end{abstract}

Keywords: Lending and Settlement of Non Performing Loans

\section{PENDAHULUAN}

Sejak berlakunya Undang-undang No. 7 Tahun 1992 dan telah diperbaharui menjadi Undang-undang No. 10 Tahun 1992, jenis bank yang diakui secara resmi hanya terdiri dari 2(dua) jenis yaitu Bank Umum dan Bank Perkreditan Rakyat. Bank Perkreditan Rakyat didefinisikan oleh Undang-Undang No 10 Tahun 1998 Pasal 1 tentang Perbankan sebagai berikut : "Bank Perkreditan Rakyat adalah Bank yang melaksanaan kegiatan usahanya secara konvensional atau berdasarkan prinsip syariah yang dalam kegiatannya tidak memberikan jasa dalam lalu lintas pembayaran"

Perbedaan BPR dengan Bank Umum adalah kegiatannya lebih terbatas dan tidak boleh menerima simpanan dalam bentuk giro, ikut kliring dan melaksanakan transaksi valuta asing, serta tidak menyediakan jasa dalam lalu lintas pembayaran.

Sebagai salah satu lembaga keuangan yang ada di tingkat masyarakat pedesaan, BPR memiliki peran yang sangat besar dalam menunjang 
perekonomian masyarakat. Hal itu didasari karena sampai ini tidak ada lembaga keuangan secara khusus mengkonsentrasikan diri kepada permodalan uasaha masyrakat menengah ke bawah.

Sebagai lembaga yang memberikan fasilitas kredit maka PT. BPR Batang Kapas akan memperoleh pendapatan utama berupa bunga kredit dan pendapatan lainnya, dengan konsekuensi akan menanggung berbagai resiko, artinya bank menderitakerugian jika fasilitas yang telah dinikmati oleh debitur tidak dapat diterima kembali oleh bank tepat pada jatuh tempo. Oleh karena itu bank membutuhkan berbagai kebijaksanaan dalam penyaluran perkreditan serta berusaha mengurangi resiko kredit seperti mengasuransikan kredit tersebut pada pihak asuransi dan analisa yang cermat terhadap calon debitur sebelum kredit dicairkan dan pengawasan kredit untuk direalisasikan.

Dari uraian di atas, penulis tertarik untuk menelitinya dan menuangkan dalam Tugas Akhir (TA) dengan judul "Aktivitas Pemberian Kredit Usaha Pada PT. Bank Perkreditan Rakyat Batang Kapas”.

1. Rumusan Masalah

Berdasarkan Latar belakang diatas maka perumusan masalahnya sebagai berikut : bagaimana Aktivitas Pemberian Kredit Usaha Pada PT. Bank Perkreditan Rakyat Batang Kapas.

2. Tujuan Penelitian

Tujuan penulis, untuk mengetahui dan memahami proses dalam pelaksanaan pemberian, pengawasan, dan perkembangan kredit pada PT. Bank Perkreditan Rakyat Batang Kapas.

3. Metode Pengumpulan Data

Penelitian yang dilakukan dengan membaca beberapa buku-buku ilmiah dan tulisan-tulisan yang berkaitan dengan pembahasan yang dilakukan dan peninjauan langsung objek penelitian untuk meneliti hasil data primer.

4. Metode Analisis Data

Dalam menganalisis data menggunakan analisis data kualititatif yang menjelaskan secara deskriptif mengenai Aktivitas Pemberian Kredit Usaha Pada PT. BPR Batang Kapas.

\section{LANDASAN TEORI}

1. Pengertian BPR

Pengertian Bank Perkreditan Rakyat (BPR) menurut Hasibuan (2004:38) adalah bank yang tidak memberikan jasa dalam lalu lintas pembayaran, yang dalam pelaksanaan kegiatan usahanya dapat secara konvensional atau berdasarkan prinsip syariah.

Bank Perkreditan Rakyat menerima simpanan hanya dalam bentuk deposito berjangka, tabungan dan bentuk lain yang dipersamakan dengan itu. Menurut pasal 13 Undang-undang RI No. 10 Tahun 1998 usaha Bank Perkreditan Rakyat (BPR) adalah :

a. Menghimpun dana dari masyarakat dalam bentuk simpanan deposito berjangka, tabungan atau bentuk lainnya yang dipersamakan dengan itu.

b. Memberikan kredit atau menyalurkannya kembali pada masyarakat (nasabah kredit). 
c. Menyediakan pembiayaan dan penempatan dana berdasarkan prinsip syariah bagi hasil sesuai dengan ketentuan yang ditetapkan oleh Bank Indonesia.

d. Menempatkan dananya dalam bentuk Sertifikat Bank Indonesia (SBI), deposito berjangka, sertifikat deposito dan atau tabungan pada bank lain.

2. Pengertian Kredit

Pengertian Kredit menurut Hasibuan (2004:87) adalah :

a. Kredit berasal dari bahasa italia, Credereyang artianya kepercayaan, yaitu kepercayaan dari kreditor bahwa debiturnya akan mengembalikan pinjaman beserta bunganya sesuai dengan perjanjian kedua belah pihak.

b. Penyediaan uang atau tagihan yang dapat dipersamakan dengan itu berdasarkan persetujuan atau kesepakatan pinjam-meninjam antara bank dengan pihak lain yanng mewajibkan pihak peminjam untuk melunasi hutangnya setelah jangka waktu tertentu dengan jumlah bunga imbalan atau pembagian hasil keuntungan.

c. Semua jenis pinjaman yang harus dibayar kembali bersama bunganya pleh peminjam sesuai dengan perjanjian yang telah disepakati.

3. Jenis-Jenis Kredit

Menurut Kasmir (2003:99) jenis-jenis kredit dibagi dalam 7 kelompok yaitu :

1. Dilihat dari segi kegunaan

a. Kredit Investasi

Biasanya digunakan untuk keperluan perluasan uasaha atau membangun proyek, pabrik baru atau untuk keperluan rehabilitasi. Contoh kredit investasi misalnya untuk membangun pabrik atau membeli mesin-mesin.

b. Kredit Modal Kerja

Digunakan untuk keperluan meningkatkan produksi dalam operasionalnya. Contoh kredit modal kerja diberikan untuk membeli bahan baku, membayar gaji pegawai atau biaya-biaya lainnya yang berkaitan dengan proses produksi perusahaan.

2. Dilihat dari segi tujuan kredit

a. Kredit Produktif

Kredit yang digunakan untuk peningkatan usaha produksi atau investasi. Kredit ini diberikan untuk menghasilkan barang atau jasa. Contoh kredit untuk membangun pabrik yang nantinya akan menghasilkan barang, kredit pertanian atau kredit pertambangan menghasilkan bahan tambang atau kredit industri lainnya.

b. Kredit Konsumtif

Kredit yang digunakan untuk konsumsi secara pribadi. Dalam kredit ini tidak ada pertambahan barang atau jasa yang dihasilkan, karena memang untuk digunakan atau dipakai oleh seseorang atau badan usaha. Sebagai contoh kredit untuk perumahan, kredit untuk mobil pribadi, kredit perabotan rumah tangga dan kredit konsumtif lainnya.

3. Analisa Kredit

Hal yang perlu diperhatikan dalam menganalisa kredit yaitu nasabah harus memenuhi prinsip 6C yaitu sebagai berikut : 


\section{Character}

Suatu keyakinan bahwa sifat atau watak dari orang - orang yang diberikan kredit benar - benar dapat dipercaya, hal ini tercermin dari latar belakang debitur baik yang bersifat latar belakang pekerjaan maupun bersifat pribadi seperi cara hidup, gaya hidup yang dianutnya, keadaan keluarga, kebiasaan dan social standingnya.

\section{Capital}

Untuk melihat penggunaan modal apakah efektif, dilihat dari laporan keuangan ( neraca dan laporan laba rugi ) dengan melakukan pengukuran seperti segi likuiditas, solvabilitas, rentabilitas dan ukuran lainnya. Capital juga harus dilihat dari sumber mana saja modal yang ada sekarang ini.

3. Capacity

Untuk melihat nasabah dalam kemampuannya dalam bidang bisnis dihubungkan dengan pendidikannya, kemampuan bisnis juga diukur dengan kemampuannya dalam memahami tentang ketentuan - ketentuan pemerintah. Begitu pula dengan kemampuannya dalam menjalankan usahanya selama ini. Pada akhirnya akan terlihat kemampuannya dalam mengembalikan kredit yang disalurkan.

\section{Collacteral}

Merupakan jaminan yang diberikan calon nasabah baik yang bersifat fisik maupun non fisik. Jaminan hendaknya melebihi jumlah kredit yang diberikan, jaminan juga harus diteliti keabsahannya sehingga jika terjadi sesuatu masalah, maka jaminan yang dititipkan akan dapat dipergunakan secepat mungkin.

5. Condition of Economy

Dalam menilai kredit hendaknya juga dinilai kondisi ekonomi dan politik sekarang dan dimasa yang akan datang sesuaisector masing-masing, serta prospek usaha dari sector yang debitur jelaskan. Penilaian prospek bidang usaha yang dibiayai hendaknya benar - benar memiliki prospek yang baik, sehingga kemungkinan kredit tersebut bermasalah relatif kecil.

6. Constraint

Adalah batasan dan hambatan yang tidak memungkinkan suatu bisnis untuk dilaksanakan pada tempat tertentu.

\section{PEMBAHASAN}

1. Pelaksanaan Dalam Pemberian kredit

a. Permohonan Kredit

Permohonan kredit harus diajukan secara tertulis dengan menggunakan format yang telah ditentukan oleh BPR Batang Kapas yang isinya memuat informasi lengkap mengenai kondisi pemohon atau calon nasabah, seperti berisi tentang nama pemohon, alamat pemohon, nama perusahaan, alamat perusahaan, jumlah permohonan pinjaman, jangka 
waktu kredit, rencana penggunaan pinjaman, agunan yang diserahkan sebagai jaminan kredit.

Disamping mengajukan permohonan kredit seperti diatas tersebut calon debitur juga memenuhi beberapa kriteria dan syarat sebagai berikut :

1) Kriteria Calon Debitur

a) Warga Neagara Indonesia yang cakap hukum ( Berusia minimal 21 Tahun atau telah menikah dan berakal sehat).

b) Mempunyai usaha yang jelas dan dpat diyakini bank.

c) Tidak tercatat dalam daftar hitam dan debitur macet yang dikeluarkan oleh Bank Indonesia.

2) Persyaratan Permohonan Kredit

a) Foto copy kartu identitas diri ( KTP/SIM/PASPOR ) yang berlaku

b) Pas photo $3 \times 4$ sebanyak 3 lembar

c) Mempuanyai perizinan sesuai dengan ketentuan yang berlaku (SIUP,TDUP,SITU).

d) Mempunyai Nomor PokokWajib Pajak (NPWP) sesuai ketentuan Bank Indonesia dan menyerahkan foto copynya.

e) Untuk calon debitur yang berbentuk serta mempunyai laporan keuangan.

b. Pemeriksaan Permohonan Kredit

Pemeriksaan permohonan kredit diidentifikasi melalui pemeriksaan keabsahan permohonan dengan kelengkapannya, pemeriksaan administrasi dan diikuti dengan pemeriksaan tentang keadaan benda jaminan, letak, luas, batas-batasnya dan lain-lain yang dirasa perlu.

Sedangkan untuk badan usaha, bank melakukan pemeriksaan kelayakan terhadap berbagai aspek diantaranya :

1) Aspek Manajemen

Pengurus atau pimpinan perusahaan harus orang-orang yang kepribadiannya tidak diragukan, berjiwa wira swasta serta mempunyai pengetahuan yang cukup mengenai bidang usahanya.

2) Aspek Pemasaran

Barang dan jasa yang akan dihasilkan harus mempunyai prospek pemasaran yang baik.

c. Analisa Kredit

Adapun analisis pemberian kredit yang dilakukan oleh BPR Batang Kapas meliputi analisis 5C

1. Waktu atau Karakter ( Character)

Untuk lebih mengetahui karakter calon debitur, analisis kredit yang dilakukan oleh PT. BPR Batang Kapas yaitu melalui wawancara terhadap calon debitur dan meminta informasi dari Bank Indonesia melalui media yang telah disediakan secara on-line.

2. Capacity

Penilaian dari kemampuan mengajukan permohonan kredit PT. BPR Batang Kapas melakukan kunjungan ke lokasi usaha dan juga berdasarkan informsi dari pihak ke tiga lainnya. 


\section{Capital}

Penilaian terhadap permodalan ( capital) calon debitur dapat diketahui analisis kredit dari lapoaran keuangan calon nasabah, serta PT. BPR Batang Kapas melihat keadaan dan situasi usaha nasabah untuk beberapa tahun yang lalu, saat ini dan kemungkinan untuk proyesksi pada masa yang akan datang.

4. Condition of Economy

Penilaian terhadap usaha calon debitur, PT. BPR Batang Kapas melihat bagaimana keadaan usaha debitur apakah aman atau tidak, dengan melihat dan meninjau keadaan usahanya dari beberapa tahun terakhir,sekarang dan masa yang akan datang. Agar mengurangi terjadinya kredit bermasalah atau kredit macet

5. Collacteral

Agunan dibutuhkan oleh PT. BPR Batang Kapas untuk berjaga-jaga atas kemingkinan terjadinya penyimpanagan penilaian terhadap faktor diatas, yang mengakiabat tidak sanggupnya nasabah untuk membayar kembali pinjaman dari usaha atau proyek yang dibiayai.

d. Persetujuan Kredit

Apabila sudah dilakukan analisa kredit, selanjutnya adalah persetujua kredit, persetujuan kredit oleh BPR Batang Kapas mencakup :

1. Jumlah uang yang diterima

2. Jangka waktu kredit.

3. Biaya-biaya yang harus dibayar.

Dalam tahap persetujuan kredit, bank mengambil keputusan atas permohonan kredit disetujui atau ditolak.

e. Realisasi Kredit

Realisasi kredit diberikan setelah disetujui kreditnya oleh pejabat bank yang berwenang, dengan membuka rekening tabungan di PT. BPR Batang Kapas. Pencairan atau pengambilan uang dari rekening sebagai realisasi dari pemberian kredit dapat diambil sesuai ketentuan dan tujuan kredit yang akan digunkan oleh debitur.

f. Pengawasan Kredit

Setelah kredit diberikan, maka tugas PT. BPR Batang Kapas selanjutnya adalah dilakukan pengawasan kredit yang mencakup upaya memeriksa kredit yang diberikannya. Apakah semua yang terjadi sesuai dengan rencana yang ditetapkan, perintah yang dikeluarkan dan prinsip yang dianut, juga dimaksud untuk mengetahui kelemahan dan kesalahan agar dapat dihindari kejadiannya di kemudian hari

\section{Perkembangan kredit}

Perkembangan serta kesuksesan PT. BPR Batang Kapas salah satunya ditentukan olehkredit usaha rakyat, dimana kredit usaha rakyat dapat mampu menumbuhkan perekonomian masyarakat Batang Kapas, melalui usaha pemberian kreditnya PT. BPR Batang Kapas harus mampu meningkatkan efisiensi dan efektivitas dalam pemberian kredit dan berusaha sebaik mungkin mengurangi resiko kredit dimasa yang akan datang. 
Berikut tabel perkembangan kredit PT. BPR Batang Kapas sebagai berikut :

Tabel 1

Perkembangan Kredit PT. BPR Batang Kapas

Periode 2013-2015

\begin{tabular}{|l|c|c|}
\hline Tahun & Usaha & Kredit yang diberikan (Miliaran Rupiah) \\
\hline 2013 & 252 & 1,541 \\
\hline 2014 & 264 & 1,612 \\
\hline 2015 & 282 & 1,721 \\
\hline
\end{tabular}

Sumber : BPR Batang Kapas, 2015

Dari data diatas, terlihat adanya peningkatan jumlah debitur disetiap tahunnya. Pada tahun 2013 kredit yang diberikan sebesar Rp 1,541 dengan jumlah debitur sebanyak 252, pada tahun 2014 kredit yang diberikannya naik menjadi Rp 1,612 dan jumlah debitur sebanyak 264 dan pada tahun 2015 jumlah kredit yang diberikan meningkatkan secara signifikan sebesar 1,725 dengan jumlah nasabah 282 Ini berarti masyarakat telah menaruh perhatian dan kepercayaan pada BPR Batang Kapas dalam pemberian kredit Usaha Rakyat.

\section{Kredit Bermasalah dan Langkah Penyelesain Kredit Bermasalah}

Kredit bermasalah terjadi karena debitur mengalami kesulitan dalam penyelesaian kewajiban-kewajibannya, baikdalam bentuk pembayaran kembali pokoknya dan atau pembayaran bunga, denda keterlambatan serta ongkosongkos bank yang menjadi beban debitur

Sebelum penulis melanjutkan tentang langkah-langkah penyelamatan kredit bermasalah, terlebih dahulu ada baiknya di lihat perkembangan kolektibiltas kredit Bank Perkreditan Rakyat (BPR) Batang Kapas dapat diliahat pada tabel 2

Tabel 2

Kolektibiltas Kredit

Bank Perkreditan Rakyat Batang Kapas

(Dalam Ribuan Rupiah)

\begin{tabular}{|c|c|c|c|c|c|c|c|}
\hline \multirow{2}{*}{ No } & \multirow{2}{*}{ Jenis Kredit } & \multicolumn{2}{|c|}{$\mathbf{2 0 1 3}$} & \multicolumn{2}{c|}{$\mathbf{2 0 1 4}$} & \multicolumn{2}{c|}{$\mathbf{2 0 1 5}$} \\
\cline { 3 - 8 } & & $\mathbf{R p}$ & $\mathbf{\%}$ & $\mathbf{R p}$ & $\mathbf{\%}$ & $\mathbf{R p}$ & $\mathbf{\%}$ \\
\hline 1 & Lancar & 441.515 .000 & 89.55 & 467.720 .000 & 89,70 & 515.502 .000 & 89,03 \\
\hline 2 & Kurang Lancar & 18.260 .000 & 3,68 & 23.432 .000 & 4,49 & 27.432 .000 & 4,73 \\
\hline 3 & Diragukan & 22.289 .000 & 4,49 & 22.784 .000 & 4,36 & 28.421 .000 & 4,90 \\
\hline 4 & Macet & 13.712 .000 & 2,76 & 7.453 .000 & 1,42 & 7.630 .000 & 1,31 \\
\hline & Jumlah & 495.776 .000 & 100 & 521.389 .000 & 100 & 578.994 .000 & 100 \\
\hline \multicolumn{2}{r}{} & & 10,93 & & 10,27 & & 10,94 \\
\hline
\end{tabular}

Sumber : BPR Batang Kapas, 2015

Dari tabel diatas dapat dilihat tingkat kolektibilitas nasabah cenderung berfluktuasi. Pada tahun 2013 kategori kredit lancar sebanyak Rp. 495.776.000 dengan hitungan persen 89,55\% atau Rp. 441.515, dimana kredit bermasalah sebesar $10,93 \%$ yang terdiri atas 3,68\% kredit kurang lancar, 4,49\% diragukan, 2,76 macet dan NPL sebessar 10,93\%. Pada tahun 2014 kredit lancar sebesar 89,70\% atau Rp. 467.720.000, kurang lancar Rp 4,49, diragukan 4,36, kredit macet 1,42 dan NPL sebesar 10,27\%. Pada tahun 2015 terjadi peningkatan NPL yaitu kredit lancar turun sebesar 89,03\%, kredit 
kurang lancar naik sebesar 4,73\%, kredit diragukan naik menjadi 4,90\% dan kredit macet menjadi $1,31 \%$. Penurunan kredit bermasalah ini disebabkan karena meningkatnya pendapatan nasabah juga disebabkan karena BPR Batang Kapas memperbaiki manajemennya dalam mengelola kredit yang akan disalurkan agar dapat mengurangi terjadinya kredit bermasalah.

Ada kalanya kredit yang disalurkan oleh BPR Batang Kapas juga mengalami masalah hal ini disebabkan oleh merosotnya perekonomian yang berakibat kemampuan membayar angsuran pokok dan bunga pinjaman mengalami masalah sehingga kredit lancar menjadi kurang lancar, diragukan bahkan macet. Berikut langkah penyelesaian kredit bermasalah oleh PT. BPR Batang Kapas :

1. Memberiperingatan secara lisan

Hal yang dilakukan oleh PT. BPR Batang Kapas adalah dengan cara memperingati dengan menelepon pihak debitur, bahwa pembayaran kreditnya mulai tidak memenuhi kewajiban kepada pihak bank. Biasanya peringatan yang diberikan oleh pihak bank PT. BPR Batang Kapas sebanyak tiga kali atau masih dibatas toleransi.

2. Memberikan keringanan pembayaran bunga.

Pemberian keringanan pembayaran bunga untuk penyelesain kredit dengan kolektibilitas diragukan dan macet dengan cara pembayaran secara lunas ataupun secara angsuran. Pembayaran secara sekaligus lunas diberikan apabila debitur sanggup untuk menyelesaikan sisa kewajibannya setelah diberikan keringanan, sedangkan pembayaran secara angsuran apabila keringanan bunga/denda tersebut sanggup untuk menyelesaikan kredit dalam jangka waktu tertntu.

\section{KESIMPULAN}

1. Pengelolaan kredit pada PT. BPR Batang Kapas dimulai dari Permohonan Kredit, Pemeriksaan Permohonan Kredit, Analisa Kredit, Persetujuan Kredit, Realisasi Kredit dan Pengawasan Kredit.

2. Perkembangan kredit pada PT. BPR Batang Kapas mengalam kenaikan tiap tahunnya, ini dapat dilihat dari tabel 3.1

3. Kredit bermasalah yang terjadi pada PT. BPR Batang Kapas diakibatkan oleh debitur yang mengalami kesulitan dalam mengembalikan bunga kredit serta ongkos-ongkos bank yang menjadi beban debitur yang bersangkutan.Penyelesaian kredit bermasalah oleh PT. BPR Batang Kapas dilakukan dengan cara memberi surat tunggakan, memberikan keringanan pembayaran bunga, keringanan tunggakan pokok dan mendesak debitur untuk melakukan penjualan agunanataumelelangagunantersebut. Cara itu dilakukan oleh PT. BPR Batang Kapas agar dapat mengurangi kredit bermasalah. 


\section{DAFTAR PUSTAKA}

Alanshari, F., \& Marlius, D. (2018). Prosedur Pemberian Kredit KPR Pada PT. Bank Tabungan Negara (Persero) TBK Cabang Pembantu Bukittinggi. https://doi.org/10.31227/osf.io/rsfhc

Amelia, L., \& Marlius, D. (2018). Pengendalian Kredit Dalam Upaya Menciptakan Bank Yang Sehat Pada PT. Bank Pembangunan Daerah Sumatera Barat Cabang Utama Padang. https://doi.org/10.31227/osf.io/kpc64

Andriani, B., \& Susanto, R. (2019). Pengawasan Kredit PT. Bank Perkreditan Rakyat (BPR) Ophir Pasaman Barat. https://doi.org/10.31219/osf.io/aunvc

Baiya, \& Fernos, J. (2019). Analisis Faktor-Faktor Penyebab Kredit Macet Pada Bank Nagari Cabang Siteba. https://doi.org/10.31227/osf.io/4xuks

Darmawanto, \& Fernos, J. (2019). Prosedur Pemberian Kredit Pada Bank Nagari Cabang Sijunjung. https://doi.org/10.31227/osf.io/psqfy

Firmansyah, A., \& Fernos, J. (2019). Analisis Kredit Bermasalah Dilihat Dari Standar Non Performing Loan (NPL) Pada PT. Bank Perkreditan Rakyat (BPR) Prima Mulia Anugrah Cabang Padang. https://doi.org/10.31227/osf.io/gcj94

Hasibuan, Malayu, Dasar-Dasar Perbankan, PT. Bumi Aksara, Jakarta, 2004

Ikbal, M., \& Marlius, D. (2017). Pengaruh Jumlah Taksiran Dan Uang Pinjaman Terhadap Laba Bersih Pada PT. Pegadaian (UPC) Gurun Laweh. https://doi.org/10.31227/osf.io/uch4a

Kasmir, Bank dan Lembaga Keuangan Lainnya, PT. Raja Grafindo Persada, Jakarta, 2003

Kasmir, Dasar-Dasar Perbankan, PT. Raja Grafindo Persada, Jakarta, 2003

Orlando, A., \& Susanto, R. (2019). Mekanisme Pencairan Kredit Usaha Rakyat Pada PT. Bank Rakyat Indonesia Unit Lubuk Buaya. https://doi.org/10.31219/osf.io/zuv2y

Suhardjono, Mudrajat Kuncoro, Manajemen Perbankan, Fakultas Ekonomi UGM Yogyakarta, 2002

Suyatno, Thomas, Dasar-Dasar Perkreditan, PT. Gramedia Pustaka Utama, Jakarta, 2003 
Undang-Undang RI No.10 Tahun 1998 Tentang Perbankan, Citra Umbara, Bandung, 2002 